\title{
CORRIGENDUM
}

\section{Routine stair climbing in place of residence and body mass index: a pan-European population based study}

ED Shenassa, M Frye, M Braubach and C Daskalakis

International Journal of Obesity (2008) 32, 396; doi:10.1038/sj.ijo.0803786

Correction to: International Journal of Obesity advance online publication, 23 October 2007; doi: 10.1038/sj.ijo.0803755

The authors omitted to state the following in the article.

'Dr Daskalakis was partially supported by funding from the
Pennsylvania Department of Health, through a grant to Thomas Jefferson University's Center of Excellence for Research on Obesity'.

The authors apologize for the omission. 